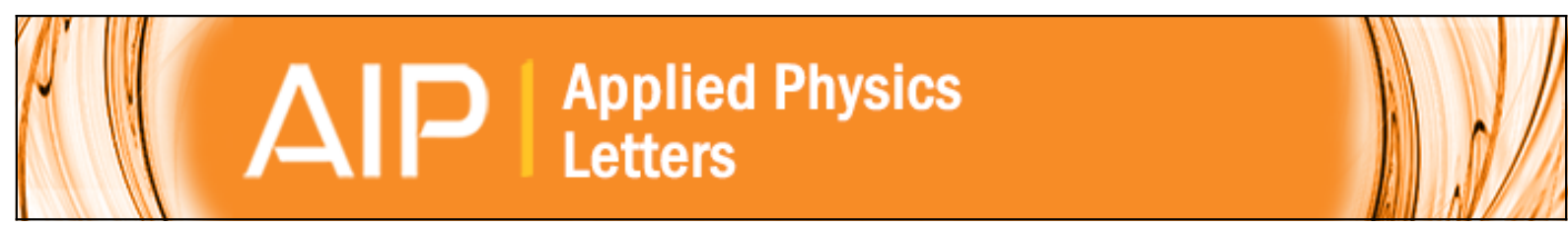

\title{
High optical and structural quality of GaN epilayers grown on ( $2^{-} 01$ ) $\beta-G a 2 O 3$
}

M. M. Muhammed, M. Peres, Y. Yamashita, Y. Morishima, S. Sato, N. Franco, K. Lorenz, A. Kuramata, and I. S. Roqan

Citation: Applied Physics Letters 105, 042112 (2014); doi: 10.1063/1.4891761

View online: http://dx.doi.org/10.1063/1.4891761

View Table of Contents: http://scitation.aip.org/content/aip/journal/apl/105/4?ver=pdfcov

Published by the AIP Publishing

\section{Articles you may be interested in}

Structural and optical properties of AlxGa1-xN/GaN high electron mobility transistor structures grown on $200 \mathrm{~mm}$ diameter Si(111) substrates

J. Vac. Sci. Technol. B 32, 021206 (2014); 10.1116/1.4866429

Influence of crystal quality of underlying GaN buffer on the formation and optical properties of InGaN/GaN quantum dots

Appl. Phys. Lett. 95, 101909 (2009); 10.1063/1.3224897

Structural and morphological properties of GaN buffer layers grown by ammonia molecular beam epitaxy on SiC substrates for AIGaN/GaN high electron mobility transistors

J. Appl. Phys. 103, 093529 (2008); 10.1063/1.2919163

Optical properties of AIGaN/GaN multiple quantum well structure by using a high-temperature AIN buffer on sapphire substrate

J. Appl. Phys. 99, 023513 (2006); 10.1063/1.2161941

GaN homoepitaxy by metalorganic chemical-vapor deposition on free-standing GaN substrates

Appl. Phys. Lett. 77, 1858 (2000); 10.1063/1.1311596

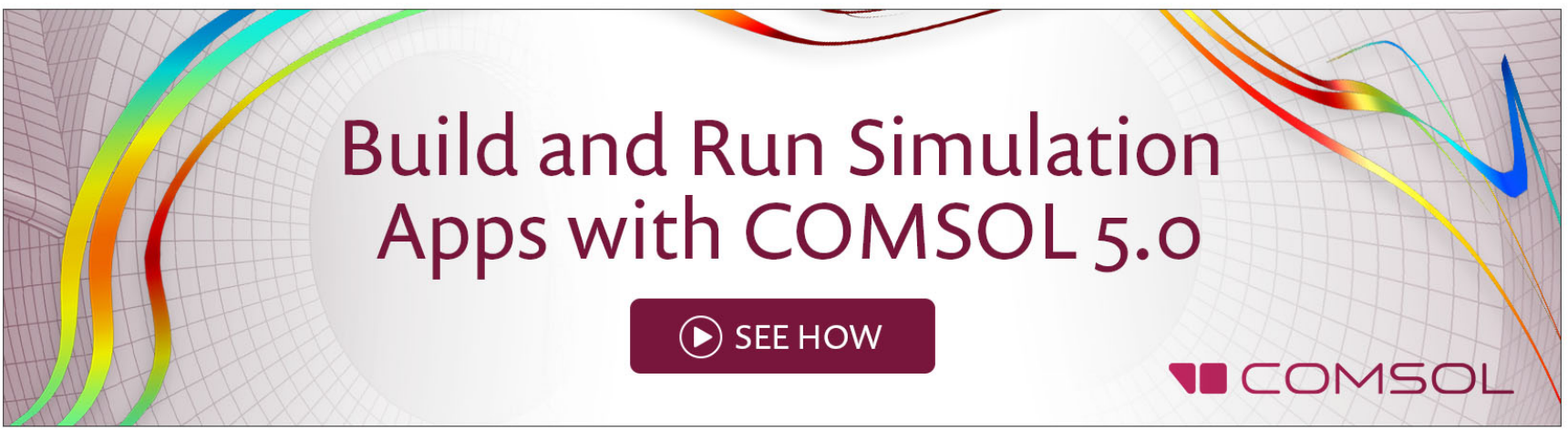




\title{
High optical and structural quality of $\mathrm{GaN}$ epilayers grown on (201) $\beta-\mathrm{Ga}_{2} \mathrm{O}_{3}$
}

\author{
M. M. Muhammed, ${ }^{1}$ M. Peres,${ }^{2}$ Y. Yamashita, ${ }^{3}$ Y. Morishima, ${ }^{3}$ S. Sato, ${ }^{3}$ N. Franco, ${ }^{2}$ \\ K. Lorenz, ${ }^{2}$ A. Kuramata, ${ }^{3}$ and I. S. Roqan ${ }^{1, a)}$ \\ ${ }^{1}$ Physical Sciences and Engineering Division, King Abdullah University of Science and Technology (KAUST), \\ Thuwal 23955-6900, Saudi Arabia \\ ${ }^{2}$ IPFN, Instituto Superior Técnico (IST), Campus Tecnológico e Nuclear, Estrada Nacional 10, \\ P-2695-066 Bobadela LRS, Portugal \\ ${ }^{3}$ Tamura Corporation, Sayama, Saitama 350-1328, Japan
}

(Received 8 July 2014; accepted 20 July 2014; published online 31 July 2014)

\begin{abstract}
Producing highly efficient GaN-based optoelectronic devices has been a challenge for a long time due to the large lattice mismatch between III-nitride materials and the most common substrates, which causes a high density of threading dislocations. Therefore, it is essential to obtain alternative substrates with small lattice mismatches, appropriate structural, thermal and electrical properties, and a competitive price. Our results show that (201) oriented $\beta-\mathrm{Ga}_{2} \mathrm{O}_{3}$ has the potential to be used as a transparent and conductive substrate for GaN-growth. Photoluminescence spectra of thick GaN layers grown on (201) oriented $\beta-\mathrm{Ga}_{2} \mathrm{O}_{3}$ are found to be dominated by intense bandedge emission. Atomic force microscopy studies show a modest threading dislocation density of $\sim 10^{8} \mathrm{~cm}^{-2}$. $\mathrm{X}$-ray diffraction studies show the high quality of the single-phase wurtzite GaN thin film on $(\overline{2} 01)$ $\beta-\mathrm{Ga}_{2} \mathrm{O}_{3}$ with in-plane epitaxial orientation relationships between the $\beta-\mathrm{Ga}_{2} \mathrm{O}_{3}$ and the $\mathrm{GaN}$ thin film defined by (010) $\beta-\mathrm{Ga}_{2} \mathrm{O}_{3} \|(11 \overline{2} 0) \mathrm{GaN}$ and (201) $\beta-\mathrm{Ga}_{2} \mathrm{O}_{3} \|(0001) \mathrm{GaN}$ leading to a lattice mismatch of $\sim 4.7 \%$. Complementary Raman spectroscopy indicates that the quality of the GaN epilayer is high. (C 2014 AIP Publishing LLC. [http://dx.doi.org/10.1063/1.4891761]
\end{abstract}

III-nitride materials, in particular, GaN, are attractive because of their large direct energy bandgap and their high thermal stability properties. They are used in numerous optoelectronic and electronic applications, such as laser diodes (LDs), visible and ultraviolet (UV) detectors, and lightemitting diodes (LEDs). ${ }^{1-4}$ Despite the wide use of GaN materials, much effort is still being devoted to improving the optical efficiency and stability of III-nitride materials. A major issue concerning device performance of III-nitrides is the introduction of high densities of threading dislocations (TDs) and other defects such as stacking faults, grain boundaries, and point defects that act as nonradiative recombination "deep state defects." ${ }^{5-7}$ These deep sites trap carriers and significantly reduce radiative electron-hole pair recombinations. ${ }^{8}$

III-nitride materials are fabricated on sapphire $\left(\mathrm{Al}_{2} \mathrm{O}_{3}\right)$, $\mathrm{SiC}$, or $\mathrm{Si}$ substrates. Researchers have achieved improvements in growth techniques, including dislocation reduction due to epitaxial lateral overgrowth or even growth on bulk GaN. ${ }^{9}$ However, sapphire, the most commonly used transparent substrate is electrically insulating and has a 14\% lattice mismatch, which leads to high dislocation densities (TDDs). ${ }^{10}$ Another routinely used substrate, $\mathrm{SiC}$, has a much smaller lattice mismatch $(3.1 \%)^{11}$ due to higher thermal and electrical conductivities, providing good stability. However, the poor surface morphology of $\mathrm{SiC}$ creates defects in the $\mathrm{GaN}$ epilayer. In addition, $\mathrm{SiC}$ is expensive and has high optical losses due to the lack of transparency. ${ }^{12}$ It is therefore important to find alternative suitable substrates that have good lattice-match to provide high-quality materials with low density of TDs and point defects and appropriate

\footnotetext{
${ }^{\text {a) }}$ Author to whom correspondence should be addressed. Electronic mail: iman.roqan@kaust.edu.sa
}

thermal, optical, and electrical properties with simplified device structure.

Monoclinic $\beta-\mathrm{Ga}_{2} \mathrm{O}_{3}$ is a good candidate as a substrate for the growth of III-nitride materials, in particular, $\mathrm{GaN}$. The lattice mismatch between $\beta-\mathrm{Ga}_{2} \mathrm{O}_{3}$ and $\mathrm{GaN}$ was found to be small (a minimum in-plane mismatch of about $2.6 \%$ for the in-plane epitaxial relationship (011) $\beta-\mathrm{Ga}_{2} \mathrm{O}_{3}$ \| (1010) GaN). ${ }^{13} \mathrm{Ga}_{2} \mathrm{O}_{3}$ has other advantages over other substrates, including high conductivity ( $\mathrm{Sn}$ dopants increases its conductivity to be $\left.\sim 1 \mathrm{~S} \mathrm{~cm}^{-1}\right)^{14}$ and high transparency in the visible and UV spectral regions due to its wide band gap $(4.8 \mathrm{eV}),{ }^{15}$ thus combining the advantages of $\mathrm{Al}_{2} \mathrm{O}_{3}$ and $\mathrm{SiC}$ substrates. Preliminary studies on the molecular beam epitaxial (MBE) growth of $\mathrm{GaN}$ on monoclinic (100) $\beta-\mathrm{Ga}_{2} \mathrm{O}_{3}$ have already been reported, although they showed low GaN quality and low reproducibility ${ }^{16}$ because of the cleavage of the $\mathrm{Ga}_{2} \mathrm{O}_{3}$ (100) plane, which causes the striping of the epilayer and substrate. Currently, the growth of $\mathrm{GaN}$ on the (201) plane of $\mathrm{Ga}_{2} \mathrm{O}_{3}$ is under investigation for the development of InGaN LEDs. ${ }^{17}$

In this work, we study a high-quality GaN epilayer grown on monoclinic $\beta$ - $\mathrm{Ga}_{2} \mathrm{O}_{3}$ by metal organic chemical vapor deposition (MOCVD). We show that (201) $\beta-\mathrm{Ga}_{2} \mathrm{O}_{3}$ is a promising substrate for III-nitride-based devices as we found that the in-plane lattice mismatch between the $(\overline{2} 01)$ plane of $\beta-\mathrm{Ga}_{2} \mathrm{O}_{3}$ and the (0002) plane of $\mathrm{GaN}$ is as low as $4.7 \%$, which results in a high-quality GaN epilayer with a low TDD and a high internal quantum efficiency.

A $0.48 \mu \mathrm{m}$ thick AlN buffer layer was grown on (201)oriented $\beta-\mathrm{Ga}_{2} \mathrm{O}_{3}$ at $500^{\circ} \mathrm{C}$ under a $\mathrm{N}_{2}$ and $\mathrm{NH}_{3}$ atmosphere. Then, after changing the carrier gas from $\mathrm{N}_{2}$ to $\mathrm{H}_{2}$, the substrate temperature was increased to $1020^{\circ} \mathrm{C}$ to grow a layer of $\mathrm{GaN}$ followed by another increase to $1080^{\circ} \mathrm{C}$ to grow 
another GaN layer. The total thickness of GaN on the AlN buffer layer was $3 \mu \mathrm{m}$. The MOCVD growth conditions are detailed in Ref. 18. A commercial (Lumilog) GaN film with a low TDD $\left(4 \times 10^{7} \mathrm{~cm}^{-2}\right)$ grown on sapphire $\left(\mathrm{GaN} / \mathrm{Al}_{2} \mathrm{O}_{3}\right)$ by MOCVD was used to compare the quality of the sample.

$\mathrm{X}$-ray diffraction (XRD) measurements were carried out to examine the epitaxial relationship of the film and substrate, the structural properties, and the strain. The XRD measurements were performed on a Bruker D8 AXS diffractometer using a $\mathrm{Cu} \mathrm{K}_{\alpha 1}$ line, a 2-bounce Ge (220) monochromator, and a Göbel mirror. Asymmetric reciprocal space maps (RSMs) were acquired using a $0.1 \mu$ m wide slit placed in front of a scintillation detector. Rocking curves (RCs) and pole figures were acquired using the open detector. Room temperature (RT) Raman measurements were carried out in the Horiba LabRam ARAMIS micro-Raman system with backscattering geometry. The samples were excited by a $473 \mathrm{~nm}$ diode laser and the data were collected by a monochromator equipped with 1800 lines/mm grating and a CCD camera cooled by liquid nitrogen. The surface morphology, roughness, and microstructural defects of the epilayers were investigated by atomic force microscopy (AFM) using the scanning probe microscope, Agilent 5400. Photoluminescence (PL) was measured to investigate the optical properties of the $\mathrm{GaN}$ film using a $325 \mathrm{~nm} \mathrm{He}-\mathrm{Cd}$ laser. The spectra were detected by an Andor monochromator attached to a CCD camera. The samples were mounted in a closed-cycle Helium cryostat for low-temperature PL (6 K).

The $2 \theta-\theta$ XRD scan in Fig. 1(a) shows the diffraction pattern of the $\mathrm{GaN} / \beta-\mathrm{Ga}_{2} \mathrm{O}_{3}$ sample, revealing the $\beta-\mathrm{Ga}_{2} \mathrm{O}_{3}$ substrate diffraction peaks at $(\overline{2} 01),(\overline{4} 02),(\overline{6} 03),(\overline{8} 04),(\overline{10} 05)$. Symmetric reflections (0002), (0004) and (0006) were observed, as expected for a single crystalline, c-plane oriented wurtzite $\mathrm{GaN}$ film. The GaN lattice parameters of the two samples were determined using the Bond method ${ }^{19}$ by measuring the (0004) and (1014) symmetric and asymmetric RCs. The measurements yielded values of $c=5.187(1) \AA$ and $\mathrm{a}=3.185(1) \AA$ and $\mathrm{c}=5.192(1) \AA$ and $\mathrm{a}=3.181(1) \AA$ for $\mathrm{GaN} / \mathrm{Ga}_{2} \mathrm{O}_{3}$ and $\mathrm{GaN} / \mathrm{Al}_{2} \mathrm{O}_{3}$, respectively, showing slight
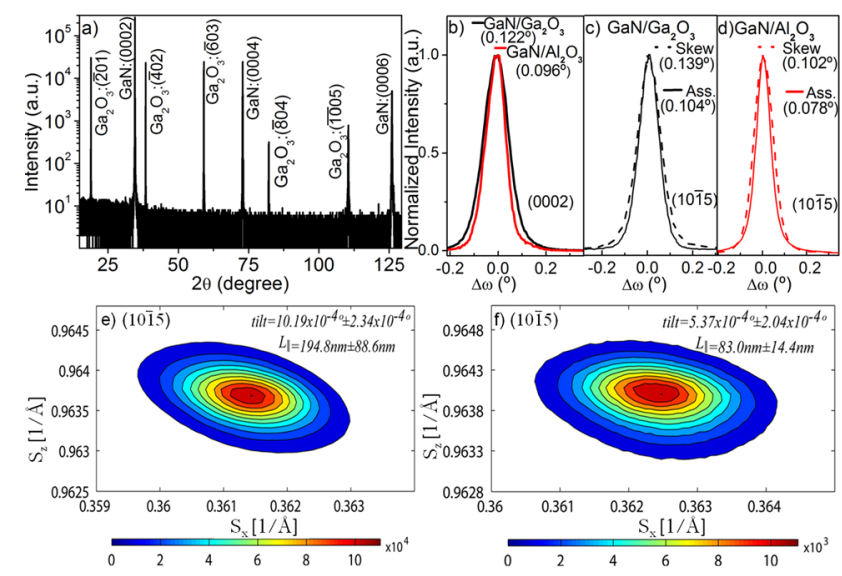

FIG. 1. (a) The $\theta-2 \theta \mathrm{XRD}$ curve of the $\mathrm{GaN} / \mathrm{Ga}_{2} \mathrm{O}_{3}$ epilayer. (b) The rocking curve around (0002) for $\mathrm{GaN} / \mathrm{Ga}_{2} \mathrm{O}_{3}$ and $\mathrm{GaN} / \mathrm{Al}_{2} \mathrm{O}_{3}$ epilayers and FWHM is shown in the bracket. (1015) Rocking curves taken with asymmetric and skew symmetric geometries for (c) $\mathrm{GaN} / \mathrm{Ga}_{2} \mathrm{O}_{3}$ and (d) $\mathrm{GaN} / \mathrm{Al}_{2} \mathrm{O}_{3}$ having a FWHM as shown in the brackets. (1015) Reciprocal space maps for (e) $\mathrm{GaN} / \mathrm{Ga}_{2} \mathrm{O}_{3}$ and (f) $\mathrm{GaN} / \mathrm{Al}_{2} \mathrm{O}_{3}$. compressive strain in both samples $\left(\varepsilon^{\mathrm{xx}}=-0.12(3) \%\right.$ and $\varepsilon^{\mathrm{zz}}=0.04(2) \%$ for $\mathrm{GaN} / \mathrm{Ga}_{2} \mathrm{O}_{3}$ and $\varepsilon^{\mathrm{xx}}=-0.24(3) \%$ and $\left.\varepsilon^{\mathrm{zz}}=0.14(2) \% \mathrm{GaN} / \mathrm{Al}_{2} \mathrm{O}_{3}\right)$. The strain was calculated assuming strain-free lattice parameters of $\mathrm{a}=0.18878 \AA$ and $\mathrm{c}=5.18500 \AA \AA^{20}$ The strain ratio, $\varepsilon^{\mathrm{zz}} / \varepsilon^{\mathrm{xx}}$, should be constant in samples where only biaxial strain is present and for this case a value of $\varepsilon^{\mathrm{zz}} / \varepsilon^{\mathrm{xx}}=-0.6$ was estimated by Kisielowski et al. ${ }^{20}$ In the present case, we find strain ratios of $\varepsilon^{\mathrm{zz}} / \varepsilon^{\mathrm{xx}}=-0.3(1)$ and $\varepsilon^{\mathrm{zz}} / \varepsilon^{\mathrm{xx}}=-0.6(1)$ for $\mathrm{GaN} / \mathrm{Ga}_{2} \mathrm{O}_{3}$ and $\mathrm{GaN} / \mathrm{Al}_{2} \mathrm{O}_{3}$, respectively, suggesting that a hydrostatic strain component cannot be disregarded in our $\mathrm{GaN} / \mathrm{Ga}_{2} \mathrm{O}_{3}$ sample. Such hydrostatic strain may be introduced by defects or impurities. Figs. 1(b) -1 (d) show the XRD RCs around the GaN (0002) and (1015) reflections in the samples grown on $\mathrm{Ga}_{2} \mathrm{O}_{3}$ and $\mathrm{Al}_{2} \mathrm{O}_{3}$. The FWHM for the plots are shown in the brackets. For (1015), the measurements were performed with asymmetric as well as skew symmetric geometries. The values for the integral breadth ranging from $0.10^{\circ}$ to $0.14^{\circ}$ for $\mathrm{GaN} / \mathrm{Ga}_{2} \mathrm{O}_{3}$ are indicated in the figures and reveal the good quality of both samples with typical values for state-of-the-art films. The broadening of RCs in $\mathrm{GaN}$ is typically associated with the mosaicity and dislocation density of the films. In particular, the (0002) RCs are broadened by mosaic tilt caused by screwtype and mixed dislocations (as well as the lateral coherence length), while the (1015) reflection is also sensitive to edgetype dislocations (causing twist) when measured with the skew symmetric geometry. ${ }^{21}$ The two samples show very similar behavior with only slightly higher values for the sample grown on $\mathrm{Ga}_{2} \mathrm{O}_{3}$ suggesting slightly higher dislocation densities, an impressive result for initial growth experiments with little optimization of growth parameters. The mosaicity was further studied by using the RSM of the (1015) asymmetric reflection as shown in Figs. 1(e) and 1(f). From the broadening of the reciprocal lattice points, the tilt and lateral coherence length, $\mathrm{L}_{\|}$, were estimated using the geometrical method described by Fewster. ${ }^{22}$ In both samples, the tilt was very low, suggesting that the lateral coherence length contributes considerably to the broadening (see Figs. 1(e) and 1(f)). In fact, the tilt of the $\mathrm{GaN} / \mathrm{Ga}_{2} \mathrm{O}_{3}$ layer was lower than that of the $\mathrm{GaN} / \mathrm{Al}_{2} \mathrm{O}_{3}$ reference sample while the lateral coherence length was smaller, which also suggests that the main broadening of the (0002) RC (Fig. 1(b)) in $\mathrm{GaN} / \mathrm{Ga}_{2} \mathrm{O}_{3}$ was due to a small lateral coherence length. XRD pole figures were acquired on the $\mathrm{GaN} / \mathrm{Ga}_{2} \mathrm{O}_{3}$ sample by fixing the detector at an angle of $2 \theta=48.27^{\circ}$ to measure the reflections of the $\{10 \overline{1} 2\}$ family of planes for $\mathrm{GaN}$ and the $\{\overline{5} 11\}$ and $\{\overline{5} 10\}$ planes for the case of $\beta-\mathrm{Ga}_{2} \mathrm{O}_{3}$ simultaneously (Fig. 2). The epitaxial orientation relationships between the $\beta-\mathrm{Ga}_{2} \mathrm{O}_{3}$ and the $\mathrm{GaN}$ thin film are defined by (010) $\beta-\mathrm{Ga}_{2} \mathrm{O}_{3} \|(11-20)$ $\mathrm{GaN}$ and (201) $\beta-\mathrm{Ga}_{2} \mathrm{O}_{3} \|(0001) \mathrm{GaN}$, resulting in a lattice mismatch of $\sim 4.7 \%$.

The termination of TDs in the epilayer surface is indicated by small pits in the AFM scan. A wide scan of the surface morphology is shown in Fig. 3(a). Fig. 3(b) shows a higher-resolution AFM image. The average density of TDs is found to be $\sim 10^{8} \mathrm{~cm}^{-2}$ (by averaging over 20 images taken at different positions on a 2 -in. wafer), which is relatively low compared with the TDDs reported in early works on GaN epilayers grown on other substrates. ${ }^{23,24}$ The TDD of GaN epilayers grown on $\mathrm{Al}_{2} \mathrm{O}_{3}$ varies typically in the range 


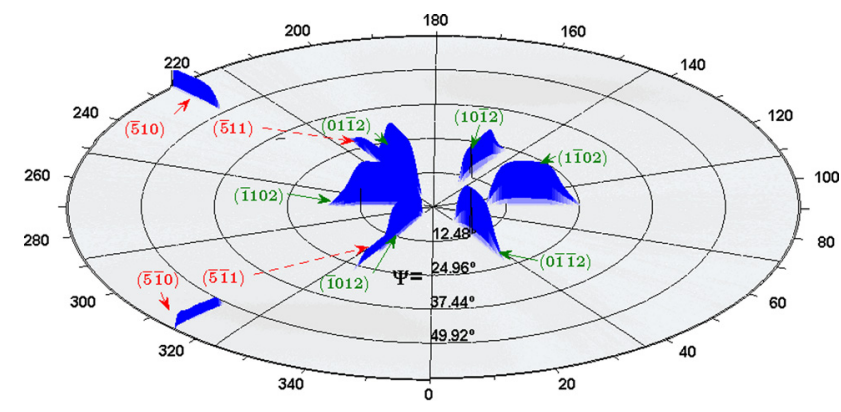

FIG. 2. A pole figure showing the $\{10 \overline{1} 2\}$ family of planes for GaN and the $\{\overline{5} 11\}$ and $\{\overline{5} 10\}$ planes for the case of $\mathrm{Ga}_{2} \mathrm{O}_{3}$.

of $10^{8}-10^{10} \mathrm{~cm}^{-2}$ and our reference sample shows a low TDD of $4 \times 10^{7} \mathrm{~cm}^{-2}$. This low value is in agreement with the slightly lower $\mathrm{RC}$ widths described above compared to the $\mathrm{GaN} / \mathrm{Ga}_{2} \mathrm{O}_{3}$ layer. More sophisticated research approaches like patterning the substrates and optimized multistep MOCVD techniques have reduced the TDD to a value of $\sim 10^{-6} \mathrm{~cm}^{-2} \cdot{ }^{25,26} \mathrm{We}$ suggest that this TDD can be reduced significantly using $(\overline{2} 01) \beta-\mathrm{Ga}_{2} \mathrm{O}_{3}$ substrates and controlling the growth process and specifications of the buffer layer and the film.

Large differences in the magnitude of Burgers vectors, especially between edge-type and screw/mixed-type dislocations, imply that the size of the surface pits should be different depending on the type of dislocation. ${ }^{27} \mathrm{We}$ could not clearly identify any screw type (the largest pits) in agreement with the low tilt values estimated from XRD. We mainly noticed mixed dislocations (medium pits) and edge dislocations (smallest pits) at a ratio of $2: 3$ per $\mu \mathrm{m}^{2}$. Medium-sized pits have a maximum depth of $\sim 7 \mathrm{~nm}$ and a width of $\sim 40 \mathrm{~nm}$; small pits are about $20 \mathrm{~nm}$ wide and have a maximum depth of $\sim 0.6 \mathrm{~nm}$. The stepped surface morphology exhibits atomic terraces $\sim 0.2 \mathrm{~nm}$ in height. The root mean square (RMS) roughness is found to be as low as $\sim 0.68 \mathrm{~nm}$ over $100 \mu \mathrm{m}^{2}$, which indicates a very smooth surface compared to the reference sample (with a RMS roughness of $\sim 0.87 \mathrm{~nm})$.

Figs. 4(a) and 4(b) show RT and low-temperature (6K) PL spectra of $\mathrm{GaN} / \mathrm{Ga}_{2} \mathrm{O}_{3}$, respectively, compared to $\mathrm{GaN} / \mathrm{Al}_{2} \mathrm{O}_{3}$. The RT PL spectrum of $\mathrm{GaN} / \beta-\mathrm{Ga}_{2} \mathrm{O}_{3}$ has a dominant intensity near the bandedge emission centered at $3.41 \mathrm{eV}$ and a very weak yellow luminescence emission. The bandedge emission presents a combination of free exciton transition, donor-bound exciton transition, and donor-to-valence band transition. ${ }^{28-30}$ Surprisingly, the ratio of the PL intensity at $6 \mathrm{~K}$ to that at RT, found to be $\sim 2.7: 1$, is better than that of the $\mathrm{GaN} / \mathrm{Al}_{2} \mathrm{O}_{3}$ ( 20:1) and is similar to that in undoped $\mathrm{GaN} / \mathrm{Al}_{2} \mathrm{O}_{3}$ epilayers

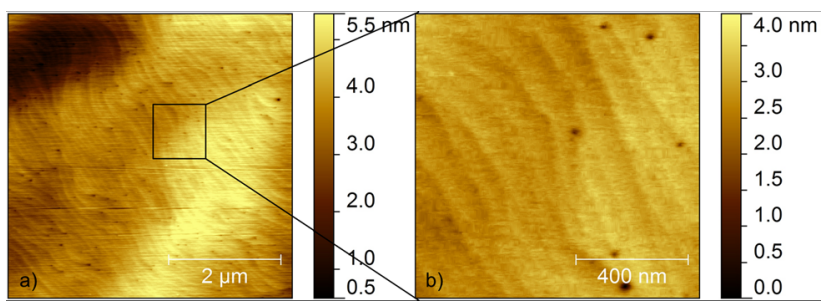

FIG. 3. (a) This $5 \times 5 \mu \mathrm{m}^{2}$ AFM image of the $\mathrm{GaN} / \mathrm{Ga}_{2} \mathrm{O}_{3}$ and (b) $1 \times 1 \mu \mathrm{m}^{2}$ AFM image of the $\mathrm{GaN} / \mathrm{Ga}_{2} \mathrm{O}_{3}$ sample.
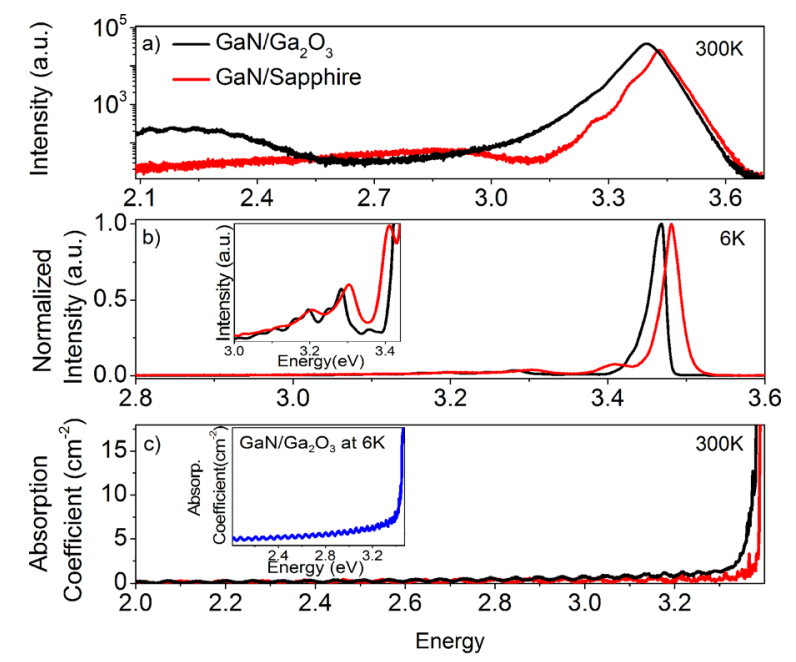

FIG. 4. (a) (Log scale) PL spectra at RT and (b) (linear scale) normalized PL spectra at $6 \mathrm{~K}$, and the absorption spectra (uncorrected spectra for reflection) (c) at $\mathrm{RT}$ for both the $\mathrm{GaN} / \mathrm{Ga}_{2} \mathrm{O}_{3}$ and $\mathrm{GaN} / \mathrm{Al}_{2} \mathrm{O}_{3}$ epilayers (the inset shows the absorption spectrum of $\mathrm{GaN} / \mathrm{Ga}_{2} \mathrm{O}_{3}$ at $6 \mathrm{~K}$ ).

reported in the literature. ${ }^{31}$ The bandedge intensity of GaN/ $\mathrm{Ga}_{2} \mathrm{O}_{3}$ wafer is 1.5 times stronger at RT than that from the $\mathrm{GaN} / \mathrm{Al}_{2} \mathrm{O}_{3}$ wafer, although the TDD of the later is lower. This suggests that other defects that create a high density of nonradiative deep states (such as point defects or other structural defects) are suppressed significantly, resulting in much higher intensity. Fig. 4(b) shows an intense band edge emission at $6 \mathrm{~K}$. The bandedge peak of $\mathrm{GaN} / \mathrm{Ga}_{2} \mathrm{O}_{3}$ is redshifted compared to that of the film on $\mathrm{Al}_{2} \mathrm{O}_{3}$, in agreement with the lower compressive strain observed by XRD in the former. However, the peak wavelength can also be influenced by doping or defects. ${ }^{20}$ The inset of Fig. 4(b) shows donor acceptor pair (DAP) peaks at $6 \mathrm{~K}$ within the energy range from $3.28 \mathrm{eV}$ to $3 \mathrm{eV}$. A series of peaks are observed, with the first peak centered at $3.29 \mathrm{eV}$ followed by the longitudinal optical (LO)-phonon replicates at low energies, with an energy difference of about $\sim 88 \mathrm{meV}$. In general, we observed that $\mathrm{GaN} / \beta-\mathrm{Ga}_{2} \mathrm{O}_{3}$ is mechanically rigid and the PL intensity remains the same even in cut pieces compared with the $\mathrm{GaN} / \mathrm{Al}_{2} \mathrm{O}_{3}$.

The optical absorption spectra of $\mathrm{GaN} / \mathrm{Ga}_{2} \mathrm{O}_{3}$ and $\mathrm{GaN} /$ $\mathrm{Al}_{2} \mathrm{O}_{3}$ at $\mathrm{RT}$ are shown in Fig. 4(c). The band gap of GaN/ $\mathrm{Ga}_{2} \mathrm{O}_{3}$ epilayer is measured as $\sim 3.4 \mathrm{eV}$ at RT, slightly blueshifted compared to bulk GaN (3.39 eV at RT). ${ }^{32}$ This slight blueshift can be due to the compressive stress. The near UV absorption is higher for the GaN epilayer grown on $\mathrm{Ga}_{2} \mathrm{O}_{3}$ than that grown on $\mathrm{Al}_{2} \mathrm{O}_{3}$, which is due to the absorption from $\mathrm{Ga}_{2} \mathrm{O}_{3}$ (figure not shown). A slight tail is shown in the absorption spectra of $\mathrm{GaN} / \mathrm{Ga}_{2} \mathrm{O}_{3}$ at $\mathrm{RT}$ and $6 \mathrm{~K}$ (inset of Fig. 4(c)), compared to that of $\mathrm{GaN} / \mathrm{Al}_{2} \mathrm{O}_{3}$. The exponential behavior in the tail of the absorption edge can be attributed to structural disorder, point defects, excitonic transitions, or inhomogeneous strain in the film, ${ }^{33}$ which can cause a broadening of the PL bandedge peak.

Fig. 5(a) shows the Raman spectrum of the $\mathrm{GaN} / \mathrm{Ga}_{2} \mathrm{O}_{3}$ epilayer and that of the $\beta-\mathrm{Ga}_{2} \mathrm{O}_{3}$ substrate as a reference to identify the GaN peaks (Fig. 5(b)). The Raman peaks of $\beta$ - $\mathrm{Ga}_{2} \mathrm{O}_{3}$ substrate (at 169.26, 199.81, 319.7, 346.89, 416.04, and $659.95 \mathrm{~cm}^{-1}$ ) are marked by asterisks. It is known that 


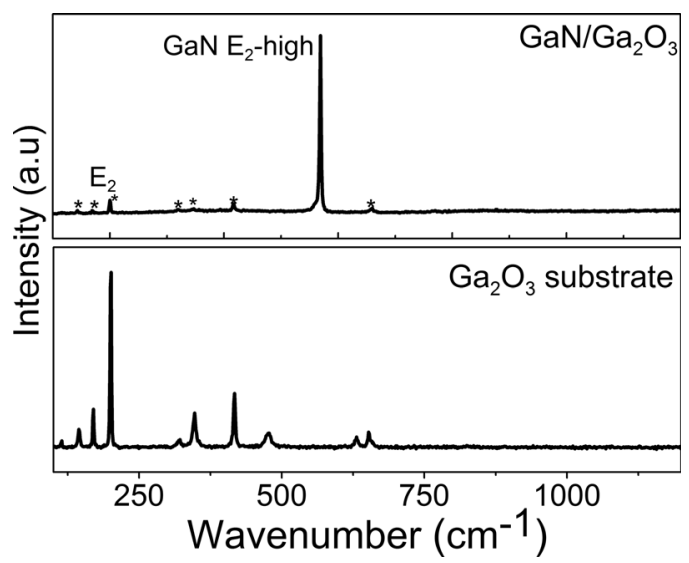

FIG. 5. The RT Raman spectra of (a) the $\mathrm{GaN} / \mathrm{Ga}_{2} \mathrm{O}_{3}$ and (b) bulk $\beta-\mathrm{Ga}_{2} \mathrm{O}_{3}$ substrate.

$\beta-\mathrm{Ga}_{2} \mathrm{O}_{3}$ is a monoclinic structure with space group symmetry, $\mathrm{C}_{2 / \mathrm{m}} \cdot{ }^{34}$ The results for $(\overline{2} 01)$-oriented $\beta-\mathrm{Ga}_{2} \mathrm{O}_{3}$ agree with the results observed by Dohy et al. ${ }^{35}$ As shown in Fig. 5 , not all the optical modes of $\beta-\mathrm{Ga}_{2} \mathrm{O}_{3}$ are observed. ${ }^{34}$ However, our observation shows that all the translational modes of bulk $\beta-\mathrm{Ga}_{2} \mathrm{O}_{3}$ are redshifted in the $\mathrm{GaN} / \mathrm{Ga}_{2} \mathrm{O}_{3}$ epilayer by $1.5-2 \mathrm{~cm}^{-1}$ when compared to bulk $\beta-\mathrm{Ga}_{2} \mathrm{O}_{3}$. Wurtzite $\mathrm{GaN}$ is a tetrahedrally coordinated semiconductor with the space group of $\mathrm{C}_{6 \mathrm{v}}^{4}$ and $\mathrm{C}_{3 \mathrm{v}}$ symmetry. It is expected that Raman active modes (one $A_{1}$, one $E_{l}$, and two $E_{2}$ ) would be observed in the GaN epilayer. ${ }^{36}$ The modes observed in this epilayer are $E_{2}$ (high) and $E_{2}$ (low) modes. The $E_{2}($ high) mode peak is clearly observed (at $569.04 \mathrm{~cm}^{-1}$ ), as shown in Fig. 5(a). The symmetry $E_{2}$ (low) mode at $143.2 \mathrm{~cm}^{-1}$ is observed and overlaps partially with the $144.4 \mathrm{~cm}^{-1}$ substrate mode $\left(\mathrm{Ga}_{2} \mathrm{O}_{3}\right)$. The detected $E_{2}$ modes verify the backscattering through the c-axis of wurtzite $\mathrm{GaN} .{ }^{37}$ We observe that the positions of these peaks compared with the positions of the peaks for $\mathrm{GaN}$ grown on $\mathrm{Al}_{2} \mathrm{O}_{3}$ are dependent on the substrate due to different strain states for different samples (data not shown). The $E_{2}$ (high) mode has been demonstrated to be sensitive to biaxial strain in GaN epilayers. ${ }^{37}$ Here, we can predict that there is a slight compressive strain because the peak exhibits a blueshift of $1.04 \mathrm{~cm}^{-1}$ compared with that of bulk GaN $\left(568 \mathrm{~cm}^{-1}\right) .{ }^{37} \mathrm{In}$ contrast, the Raman peaks of $\beta-\mathrm{Ga}_{2} \mathrm{O}_{3}$ have a redshift, which indicates a corresponding tensile stress induced in the interface. In addition, the $A_{I}$ symmetry LO-phonon mode near $735 \mathrm{~cm}^{-1}$ is not observed in the Raman spectrum of GaN/ $\mathrm{Ga}_{2} \mathrm{O}_{3}$, which may be due to the strong coupling between the $A_{1}$ mode of the LO-phonon and the carrier plasmon (LOphonon-plasmon coupling modes of electronic excitation and lattice vibrations). ${ }^{38}$ Therefore, the LO-phonon-plasmon coupling causes the Raman peaks to be broader than those of a pure LO mode. ${ }^{39}$ Furthermore, no Raman peaks related to the cubic GaN structure were observed. The Raman measurement therefore confirms the XRD finding that the GaN epilayer is a single-phase wurtzite, high-quality material.

In conclusion, we show a state-of-the-art GaN epilayer grown on $(\overline{2} 01)$ oriented $\beta-\mathrm{Ga}_{2} \mathrm{O}_{3}$ with high optical quality. The epitaxial relationship between the film and substrate showed low lattice mismatch (4.7\%), which led to a low density of dislocations and other defects. The XRD and Raman measurements showed a slight biaxial strain in GaN epilayers. The PL intensity was considerably higher than that of the $\mathrm{GaN} / \mathrm{Al}_{2} \mathrm{O}_{3}$. This work shows that $\beta-\mathrm{Ga}_{2} \mathrm{O}_{3}$ is a promising substrate for the growth of high-quality GaN films. Under systematically optimized growth conditions, the growth of highly efficient LEDs and LDs based on III-nitrides should be possible and will allow new device designs such as vertically structured LEDs thanks to the increased transparency and high conductivity of bulk $\beta-\mathrm{Ga}_{2} \mathrm{O}_{3}$ substrates.

The research described in this paper was supported by King Abdullah University of Science and Technology. We acknowledge support by FCT, Portugal Grants PTDC/ CTM-NAN/2156/2012 and PTDC/FIS-NAN/0973/2012, and Investigator FCT. We thank D. Faye (IST) for the confirmation of our bond measurements.

${ }^{1}$ L. Shen, S. Heikman, B. Moran, R. Coffie, N. Q. Zhang, D. Buttari, I. P. Smorchkova, S. Keller, S. P. DenBaars, and U. K. Mishra, IEEE Electron Device Lett. 22(10), 457-459 (2001).

${ }^{2}$ A. Chini, D. Buttari, R. Coffie, L. Shen, S. Heikman, A. Chakraborty, S. Keller, and U. K. Mishra, IEEE Electron Device Lett. 25(5), 229-231 (2004).

${ }^{3}$ B. Butun, J. Cesario, S. Enoch, R. Quidant, and E. Ozbay, Photonics Nanostruct. Fundam. Appl. 5(2-3), 86-90 (2007).

${ }^{4}$ S. Butun, M. Gökkavas, H. Yu, and E. Ozbay, Appl. Phys. Lett. 89(7), 073503 (2006).

${ }^{5}$ C. Stampfl and C. G. Van de Walle, Phys. Rev. B 57(24), R15052-R15055 (1998).

${ }^{6}$ T. L. Tansley and R. J. Egan, Phys. Rev. B 45(19), 10942-10950 (1992).

${ }^{7}$ T. Sugahara, H. Sato, M. S. Hao, Y. Naoi, S. Kurai, S. Tottori, K. Yamashita, K. Nishino, L. T. Romano, and S. Sakai, Jpn. J. Appl. Phys, Part 2 37(4A), L398-L400 (1998).

${ }^{8}$ S. F. Chichibu, H. Marchand, M. S. Minsky, S. Keller, P. T. Fini, J. P. Ibbetson, S. B. Fleischer, J. S. Speck, J. E. Bowers, E. Hu et al., Appl. Phys. Lett. 74(10), 1460-1462 (1999).

${ }^{9}$ L. Marona, P. Wisniewski, P. Prystawko, I. Grzegory, T. Suski, S. Porowski, P. Perlin, R. Czernecki, and M. Leszczyński, Appl. Phys. Lett. 88(20), 201111 (2006).

${ }^{10}$ N. V. Edwards and O. Manasreh, III-Nitride Semiconductors: Electrical, Structural and Defects Properties (Elsevier, Amsterdam, 2000), pp. 287-337.

${ }^{11}$ L. Liu and J. H. Edgar, Mater. Sci. Eng., R 37(3), 61-127 (2002).

${ }^{12}$ E. G. Víllora, K. Shimamura, K. Aoki, and K. Kitamura, Thin Solid Films 500(1-2), 209-213 (2006).

${ }^{13}$ E. G. Víllora, K. Shimamura, K. Kitamura, K. Aoki, and T. Ujiie, Appl. Phys. Lett. 90(23), 234102 (2007).

${ }^{14}$ M. Orita, H. Ohta, M. Hirano, and H. Hosono, Appl. Phys. Lett. 77(25), 4166-4168 (2000).

${ }^{15}$ H. H. Tippins, Phys. Rev. 140(1A), A316-A319 (1965).

${ }^{16}$ K. Shimamura, E. G. Víllora, K. Domen, K. Yui, K. Aoki, and N. Ichinose, Jpn. J. Appl. Phys., Part 2 44(1L), L7 (2005).

${ }^{17}$ E. G. Víllora, S. Arjoca, K. Shimamura, D. Inomata, and K. Aoki, Proc. SPIE 8987, 89871U (2014).

${ }^{18}$ Y. Yamashita, Y. Morishima, S. Sato, and A. Kuramata, "Crystal growth of Ga2O3 for power device and LED applications" (unpublished).

${ }^{19}$ N. Herres, L. Kirste, H. Obloh, K. Köhler, J. Wagner, and P. Koidl, Mater. Sci. Eng., B 91-92(0), 425-432 (2002).

${ }^{20}$ C. Kisielowski, J. Krüger, S. Ruvimov, T. Suski, J. W. Ager, E. Jones, Z. Liliental-Weber, M. Rubin, E. R. Weber, M. D. Bremser et al., Phys. Rev. B 54(24), 17745-17753 (1996).

${ }^{21}$ Y. J. Sun, O. Brandt, T. Y. Liu, A. Trampert, K. H. Ploog, J. Bläsing, and A. Krost, Appl. Phys. Lett. 81(26), 4928-4930 (2002).

${ }^{22}$ P. F. Fewster, X-Ray Scattering from Semiconductors (Imperial College Press, 2003).

${ }^{23}$ S. Nakamura, Science 281(5379), 956-961 (1998).

${ }^{24}$ B. Heying, X. H. Wu, S. Keller, Y. Li, D. Kapolnek, B. P. Keller, S. P. DenBaars, and J. S. Speck, Appl. Phys. Lett. 68(5), 643-645 (1996).

${ }^{25}$ A. Usui, ECS J. Solid State Sci. Technol. 2(8), N3045-N3050 (2013).

${ }^{26}$ T. Lang, M. A. Odnoblyudov, V. E. Bougrov, A. E. Romanov, S. Suihkonen, M. Sopanen, and H. Lipsanen, Phys. Status Solidi A 203(10), R76-R78 (2006). 
${ }^{27}$ J. L. Weyher, L. Macht, G. Kamler, J. Borysiuk, and I. Grzegory, Phys. Status Solidi C 0(3), 821-826 (2003).

${ }^{28}$ H. G. Grimmeiss and B. Monemar, J. Appl. Phys. 41(10), 4054-4058 (1970).

${ }^{29}$ G. D. Chen, M. Smith, J. Y. Lin, H. X. Jiang, A. Salvador, B. N. Sverdlov, A. Botchkarv, and H. Morkoc, J. Appl. Phys. 79(5), 2675-2683 (1996).

${ }^{30}$ S. Chichibu, T. Azuhata, T. Sota, and S. Nakamura, J. Appl. Phys. 79(5), 2784-2786 (1996).

${ }^{31}$ J. Mickevičius, G. Tamulaitis, M. Shur, M. Shatalov, J. Yang, and R. Gaska, Appl. Phys. Lett. 101, 211902 (2012).

${ }^{32}$ B. G. Streetman and S. K. Banerjee, Solid State Electronic Devices (Prentice Hall PTR, 2000).
${ }^{33}$ A. Cremades, L. Görgens, O. Ambacher, M. Stutzmann, and F. Scholz, Phys. Rev. B 61(4), 2812-2818 (2000).

${ }^{34}$ R. Rao, A. M. Rao, B. Xu, J. Dong, S. Sharma, and M. K. Sunkara, J. Appl. Phys. 98(9), 094312 (2005).

${ }^{35}$ D. Dohy, G. Lucazeau, and A. Revcolevschi, J. Solid State Chem. 45(2), 180-192 (1982).

${ }^{36}$ T. Azuhata, T. Sota, K. Suzuki, and S. Nakamura, J. Phys.: Condens. Matter 7(10), L129 (1995).

${ }^{37}$ H. Harima, J. Phys.: Condens. Matter 14(38), R967 (2002).

${ }^{38}$ T. Kozawa, T. Kachi, H. Kano, Y. Taga, M. Hashimoto, N. Koide, and K. Manabe, J. Appl. Phys. 75(2), 1098-1101 (1994).

${ }^{39}$ M. D. McCluskey and E. E. Haller, Dopants and Defects in Semiconductors (Taylor \& Francis, 2012). 